\title{
Qualidade social e políticas para a Educação Superior no Brasil
}

\section{Social quality and policies for Higher Education in Brazil}

\author{
Nadja Maria de Lima Costa*, Ana Maria Costa e Silva** \\ *Instituto Federal de Educação, Ciência e Tecnologia do Rio Grande do Norte; ** Instituto de Educação, Universidade do Minho
}

\begin{abstract}
Resumen
Este texto incide numa revisão teórica e numa reflexão acerca de referenciais de qualidade social para as políticas de educação superior brasileira. Discutir a educação superior no âmbito das políticas educacionais no Brasil requer a compreensão do fenômeno educativo em sua totalidade, considerando os mais diversos contextos da vida social e política. Nesse sentido, requer uma reflexão sobre a economia, a política, a cultura, a arte, as questões éticas, filosóficas, científicas, tecnológicas, curriculares, pedagógicas e demais dimensões da vida humana, o que será aqui fundamentado, enfatizando a importância de uma educação superior de qualidade.
\end{abstract}

\section{Abstract}

This text consists of both a theoretical review and a reflection on references about social quality for higher education policies in Brazil. Discussing higher education in the scenery of educational policies in Brazil requires a comprehension of educative phenomenon as a whole, considering the several contexts of social and political life. Accordingly, requires a reflection on economy, politics, culture, art, such as ethical, philosophical, scientific, technological, curricular and pedagogical issues, besides on further dimensions of human life; it will be emphasized the defence of a higher education that is asserted in the centrality of quality proposals with social sense and values.

Keywords: higher education, educational policies, social quality

\section{Introdução}

Debater e refletir sobre a educação superior no âmbito das políticas educacionais no Brasil abrange uma gama de complexidades e uma série de temáticas adjacentes a essa prática social. Requer, sobretudo, compreender o fenômeno educativo em sua totalidade, considerando os mais diversos contextos da vida social e política.

A educação superior, no decorrer da história, encontra-se imbricada com as temáticas de desenvolvimento social, crescimento econômico, crises econômicas, projetos sociais em disputa e formação e profissionalização com qualidade social. Implica, pois, refletir nos processos de expansão, democratização do acesso, inclusão, produção de conhecimento e de tecnologias, currículo e profissionalização docente. Indubitavelmente, é uma política educacional interconectada à compreensão de qualidade, equidade e pertinência social (Sobrinho, 2010).

Antes de quaisquer outras considerações, é valido salientar que estamos tratando da educação superior como prática social, cujo atendimento deve se fundamentar em princípios educativos basilares como, desenvolvimento humano e social, produção de conhecimento, democratização e equidade em todos os encaminhamentos com o propósito de atingir qualidade social. Nessa direção Santos (1995) afirma que a educação superior tem uma função social que pressupõe

\begin{abstract}
"Possibilitar aos sujeitos adquirir e/ou desenvolver valores positivos perante o trabalho e perante a organização social e econômica da produção; possibilitar aos sujeitos construir regras de comportamento que facilitem o desenvolvimento de interações sociais mais humanizadoras e democráticas; estimular a construção prazerosa de trajetórias pessoais de vida; estimular formas interativas de acessar informações e processar conhecimentos; estimular o desenvolvimento de habilidades cognitivas que permitam compreender e viver a realidade nas suas diversas performances; alertar para a existência e a necessidade de convivência com o diferente e o diferenciado; enfim, possibilitar que se aprenda a viver e a processar o exercício da liberdade de ser e se tornar sujeito humano, de um determinado tempo, para além de seus muros.” (Santos, 1995, p.189).
\end{abstract}

A defesa da educação superior pública se afirma na centralidade de propostas fundamentadas na qualidade com sentidos e valores sociais e reforça a sociedade como referência constante. Um pressuposto em contradição ao caráter eficientista e utilitarista que sustenta o mercado neoliberal. Na aceção da qualidade social, não é suficiente a formação de bons profissionais, é imprescindível formá-los no sentido da cidadania e formá-los sob a perspectiva de consciência da nacionalidade. A educação superior, necessariamente compromete-se com a produção de conhecimentos e de artefatos úteis, sobretudo deve reforçar/ratificar os valores da ciência e da formação humana com vista ao desenvolvimento da sociedade em sua inteireza. Deve respeitar e promover valores permanentes na humanidade como justiça social, democracia e autonomia (Ristoff, 2008).

Sob a perspetiva crítica diversos pesquisadores estabelecem um percurso das políticas educacionais com o objetivo de se compreender o desenho atual e os processos em suas construções históricas e sociais. Nessa dinâmica e em contraposição às reformas de caráter neoliberal, mercantilista e empresarial que se consolidou na sociedade brasileira, se tornam imprescindíveis alternativas baseadas em práticas democráticas, que contam com participação e discussão de soluções entre os diversos sujeitos (professores, alunos, funcionários e 
todas as classes sociais) envolvidos. Essa compreensão crítica da realidade traz possibilidades efetivas e, sobretudo, perspetiva-se capaz de constituir propostas educacionais que superem a adequação aos princípios de mercado, tendo como centralidade a formação humana, o pensamento crítico e a autonomia (Chauí, 2001).

Dada a especificidade do nível educacional em questão, a imbricação com a formação humana e sua inter-relação com a sociedade, iniciaremos uma reflexão acerca da qualidade social na educação superior. Faremos um pequeno recorte e algumas considerações para especificar a qual qualidade estamos nos reportando.

\section{Qualidade social na educação superior: um caminho a ser trilhado}

Nesta reflexão, o conceito de qualidade social é orientado por uma lógica contra-hegemônica ao desenvolvimento do capital excludente e em contraposição à conceção da qualidade total de cunho empresarial e neoliberal. A perspetiva da qualidade social na educação se origina no seio dos movimentos sociais em defesa da educação pública de qualidade e assume relevância no campo da organização pedagógica e política da prática educativa (Flach, s.d.).

Uma educação de qualidade social pressupõe organizar-se nos seguintes eixos estruturantes: educação como direito de cidadania, gestão democrática com participação popular, valorização dos trabalhadores da educação, financiamento em regime de colaboração e integração entre as políticas e outros entes jurídicos e sociais (Camini, 2001).

A qualidade social da educação constitui-se assim, em prescrição permanente, visto que significa um esforço em atualizar e construir o ser humano. Denota um processo abrangente do desenvolver-se socioculturalmente e de colocar-se à altura de sua época. Tem relação direta com a forma e os caminhos de produzir a existência humana, a história da humanidade, os conhecimentos, técnicas, valores, comportamentos e atitudes.

De acordo com Machado (2010), uma educação superior de qualidade social perpassa pelo princípio indissociável do desenvolvimento histórico da humanidade. Afirma esta autora:

\begin{abstract}
Instituições de educação superior com qualidade social reconhecem e praticam o princípio de que sua finalidade é indissociável de um projeto histórico para a humanidade como um todo. Sabem que não há verdadeiro desenvolvimento institucional sem desenvolvimento humano. Trazem, como projeto, a perspectiva transformadora e entendem que suas funções educacionais são indissociáveis de suas funções científicas, culturais e sociais (Machado, 2006. p 21).
\end{abstract}

Para atender tal princípio, as instituições de educação superior devem articular seus projetos acadêmicos às demandas da sociedade. Precisam associar as ações de ensino, pesquisa e extensão, bem como qualificar o diálogo ou interação com a sociedade, no sentido de tornar públicos os ideais que pretende realizar.

\section{Educação como direito de cidadania}

De acordo com Belloni (2003), a qualidade social como direito de cidadania está intrinsecamente pautada por uma política de inclusão social responsável e consequente, em que se assume um compromisso com a participação de todos os cidadãos na construção de uma sociedade mais justa e equânime. Sob esta focagem, a inclusão social é compreendida como essencial ao direito de exercício de cidadania à medida que, de fato, possibilita a emancipação humana e social (Flach, s.d.).

Corroborando a afirmativa que a educação de qualidade social se efetiva na prática da democracia, Belloni situa:

Educação de qualidade social é aquela comprometida com a formação do estudante com vistas à emancipação humana e social; tem por objetivo a formação de cidadãos capazes de construir uma sociedade fundada nos princípios da justiça social, da igualdade e da democracia (Belloni, 2003, p. 232).

Nesse sentido, a educação de qualidade social se constitui na prática de políticas democráticas de acesso e que garantem permanência e conclusão com êxito. Assim, aponta para as garantias de um processo formativo de democratização das relações na educação e na sociedade em geral. Para tanto, a gestão educacional nas mais diversas instâncias e níveis precisa pautar-se nos princípios democráticos da equidade, autonomia e da participação.

A qualidade social, nesta perspetiva, ultrapassa a própria escola para envolver toda a sociedade no que se refere à formação de cidadãos democráticos e ativos nas decisões de aspetos individuais e coletivos da vida cotidiana.

\section{Gestão democrática com participação popular}

Em relação à participação, se destaca a necessidade primordial de entendê-la como um apropriado exercício democrático, não podendo se reduzir a uma questão de método, em que a população é levada a contribuir na tomada de decisões, porém sem considerar os verdadeiros interesses e valores da coletividade, tendo em vista que as condições objetivas não possibilitam a real participação. Constitui-se, desse modo, participação tendenciosa e parcial que se distancia do sentido da democracia, caracterizando-se como uma ação ilusória, na qual os interesses coletivos são obscurecidos e desconsiderados (Paro, 2001). Consequentemente, torna-se enfraquecido o próprio desenvolvimento da sociedade.

Ao aprofundar o significado de participação na concretização de processos democráticos na educação e em demais segmentos sociais, o dossiê "Desafios da consolidação democrática na América Latina" procura evidenciar a expressiva riqueza e complexidade da 
experiência latino-americana. Tal sistematização visa avançar no debate sobre os desafios da consolidação democrática na contemporaneidade. Demonstra uma série de demandas urgentes na discussão sobre os vários sentidos e dimensões de "crise" social em curso e da necessidade de alternativas substantivas de seu enfrentamento nos planos estrutural e conjuntural (Guimarães, Barros \& Pinto, 2014). Neste âmbito, a educação, e em especial a de nível superior, tem fundamental papel nesta dinâmica social.

O mesmo documento oficial revela a necessidade urgente de novas formas de construção da política, de organização de matrizes sociopolíticas, na busca de equacionar a participação e representação efetivas, criando-se novos espaços de deliberação e de experimentação de novas utopias. Desvela também os desafios a serem enfrentados nas análises sobre os fenômenos no campo das ciências sociais, da teoria política e das questões democráticas (Guimarães, Barros \& Pinto, 2014).

Esse recente dossiê traz amplas contribuições no campo pedagógico e político no que diz respeito ao macro planejamentos e às políticas educacionais, tanto para o Brasil quanto para os demais países da América Latina, quiçá uma análise valiosa para o mundo. Em seus excertos finais encontra-se:

Os textos reunidos neste dossiê indicam, fundamentalmente - e parafraseando Dallmayr (2001) -, que a democracia não é um pacote de regras e procedimentos, ou simplesmente uma entre outras opções igualmente disponíveis de regime. É, antes, resposta a certos desafios e possibilidades históricas. Não é, pois, um processo construído a priori, mas "vivido" à luz das circunstâncias estruturais e valorativas singulares de cada sociedade (Guimarães, Barros \& Pinto, 2014, p.19).

Por fim, ao refletir sobre os desafios da consolidação da democracia na América Latina, o dossiê aponta que a experiência da democracia neoliberal neste continente, revestida de valores anglo-eurocêntricos e promovida como global não trouxe os resultados almejados nem prometidos, no que se refere à estabilidade democrática, desenvolvimento socioeconômico e integração regional. Como se convive com as desigualdades e se agravam as exclusões sociais, as lutas de movimentos sociais e de ativistas políticos devem se encaminhar para novas construções sociais com base na autonomia e na integração, sobretudo, considerando os territórios e culturas locais. Neste espaço social, mais uma vez, a educação ocupa centralidade fundamental.

Assim, considera-se que a qualidade social na educação se efetiva por meio da prática da democracia, iniciando-se em instâncias educativas e estendendo-se para os demais segmentos da sociedade em geral. Assim, a gestão educacional, nos mais diversos níveis e instâncias, requer a democratização das relações e dos processos, possibilitando a expressiva participação da população nas decisões sobre os assuntos da educação, qual seja por meio da escuta qualificada, da participação em conselhos e representatividades significativas. Além de demandar eleições democráticas para dirigentes de instituições educativas, incluindo deveras, os mecanismos de controle social.

\section{Valorização dos trabalhadores}

No tocante à valorização dos trabalhadores da educação na perspetiva da qualidade social, predomina a compreensão desses trabalhadores como sujeitos reais, inseridos na dinâmica social. De modo que, requerem a consideração de suas necessidades e demandas específicas do métier profissional, assim como demandam ser valorizados, por se constituírem parte essencial do processo educacional como um todo.

De acordo com Ferreira (2001), a qualidade social na educação vincula-se às questões de valorização dos profissionais do magistério, atribuindo efetivo destaque para as ações de formação continuada. No entanto, ressalta-se que as questões de valorização serão atendidas, sobretudo, a partir de uma política global de magistério sedimentada nas condições de trabalho, salário e carreira, na formação inicial e na formação continuada (Oliveira, 2004). Entretanto, as mudanças ocorridas no mundo do trabalho e as reformas educacionais, das duas últimas décadas, estabeleceram limites para a almejada valorização profissional.

Na perspectiva de Oliveira (2004), tais limites se estabelecem em virtude da lógica constituída nas políticas educacionais brasileiras das últimas décadas. Essas recaem na responsabilização dos professores pelos resultados educacionais, mediante a predominância da máxima produtivista e da avaliação de resultados, na ausência da efetivação das políticas de valorização profissional como o estabelecimento de Plano de Cargos, Carreira e Remuneração (PCCR) e mediante o atendimento, em todas as instâncias do magistério, ao Piso Salarial Profissional Nacional (Lei no 11.738/2008). Tais lacunas nas políticas públicas precarizam e intensificam o trabalho dos profissionais da educação, fragilizando questões essenciais da profissão docente como: as condições de trabalho, a carreira, a remuneração e as ações de formação continuada.

Diante do novo contexto de regulação educativa, as responsabilidades dos trabalhadores docentes aumentaram, demandando maior autonomia e exigindo maior habilidade para a solução de problemas locais e na atuação coletiva e cooperativa. Em certa medida, tais exigências ameaçam e enfraquecem as práticas e posturas heterônimias (Assunção \& Oliveira, 2009). De acordo com Freire, vive-se em um processo de superação das práticas heterônimas, que funciona como um sistema de ética no qual as normas de conduta provêm de fora. Assim, visto que a heteronomia significa dependência, submissão, obediência, a caminhada da heteronomia para a autonomia constitui-se em construção permanente (Freire, 2000).

Entretanto, na compreensão de vários pesquisadores da temática, as recentes reformas na educação brasileira a partir dos anos 1990 trouxeram uma nova dinâmica para a atuação docente. Realça, por sua vez, o protagonismo docente e a responsabilização 
dos processos da avaliação de resultados e das diferentes formas de participação individual e coletiva em processos pedagógicos e de gestão. É também componente desse novo contexto pedagógico, a ampliação dos exames nacionais, assim como uma dilatação nas formas de planejamento e gestão do currículo.

Para Oliveira (2004) ocorreu uma transferência de responsabilidades pedagógicas para os docentes, desvinculada do compromisso com as melhorias das condições de trabalho. Tais mudanças trazem implicações significativas para o trabalho docente em vários aspetos profissionais.

Essas novas demandas, sem a devida qualificação, tanto pode pôr em risco a qualidade social da educação como pode comprometer a saúde desses profissionais, haja em vista a constante solicitação, sobrecarga de trabalho coletivo e crescentes demandas diferenciadas a que são submetidos diariamente (Assunção \& Oliveira, 2009).

Ademais, a valorização dos Trabalhadores da Educação torna-se fundamental, não apenas em termos salariais, mas também e principalmente, nas formas de qualificação desses profissionais, que deve ser adequada à sua função e às necessidades da escola e do sistema em que atuam em seu conjunto. Desse modo, estabelece-se efetiva contribuição para a qualidade social da educação.

\section{Financiamento em regime de colaboração e integração}

No tocante ao financiamento em regime de colaboração na educação nacional brasileira, incidindo na qualidade social, tem-se historicamente assumido uma proposta integradora entre os sistemas federal, estadual e municipal. Entretanto, tal prática de gestão macro tem abrangência, tanto no âmbito do financiamento, quanto nos planos e ações globais e, para tanto, requer articulação de modo cooperativo (Cury, 2002).

A proposta do regime de colaboração oficializada na Constituição Federalpossui inegável amplitude e só poderá ser alcançada com considerável articulação entre os diferentes níveis educacionais. Em uma sequência pedagógica a LDB $n^{0}$ 9.394/1996 incorporou a proposição do regime de colaboração, com o objetivo de concretizar o federalismo colaborativo posto na Constituição Federal e ampliou esse regime a todos os âmbitos educacionais. Entretanto, há quase três décadas ainda perdura a carência de regulamentação que qualifique as práticas de cooperação ou normas de procedimentos.

De acordo com Dourado (2007), a ausência de Lei Complementar que regulamente o regime de colaboração entre os níveis educacionais, possibilita apenas a indução de políticas por parte do governo federal. Tal indução materializa-se por meio de programas financiados e não na consolidação dessas políticas por falta da colaboração assumida como uma responsabilidade social ou compromisso comum pela qualidade do ensino em todos os níveis.
O Plano Nacional de Educação poderia ser o instrumento de gestão pública para melhoria da qualidade social da educação nacional. Deveria efetivamente funcionar como articulador desse regime de colaboração entre os sistemas de ensino da educação brasileira. Entretanto, nesse aspeto ainda tem tido pouca efetividade (Dourado, 2007).

Segundo Luiz Araújo (2014), no atual Plano Nacional de Educação (PNE 2014-2024), sancionado em junho de 2014 com a Lei 13.005, regista-se como avanço duas referências relativas a prazos para se regulamentar a questão. O artigo 13 estabelece dois anos para a instituição de lei sobre o Sistema Nacional de Educação, que favorecerá a articulação entre os sistemas de ensino em regime de colaboração, visando efetivar as diretrizes, metas e estratégias do Plano Nacional de Educação.

Em coerência, tem-se a Estratégia 20.9, designando um prazo de dois anos para que seja regulamentado o que afirma o parágrafo único do artigo 23 e o artigo 211 da Constituição Federal. Tal procedimento regulamenta as normas de cooperação entre a União, os Estados, o Distrito Federal e os Municípios.

Com base nas considerações anteriores, reafirmamos que uma educação de qualidade social se reveste da perspectiva humanizadora, capaz de promover a emancipação humana, de colocar em prática as possibilidades de participação, a igualdade de acesso aos bens historicamente, produzidos pela humanidade e a própria educação como direito de cidadania (Paro, 2007).

Além do mais, essa perspetiva crítica de qualidade social na educação propicia a prática da gestão democrática na escola pública, viabilizando os mecanismos de participação popular e o reconhecimento dos profissionais da educação. Desse modo, conclui-se um ciclo, ao oportunizar vivências de participação e democratização nas decisões. Consolida-se assim, a gestão compartilhada e a formação cidadã tanto para os educadores quanto para os estudantes (Paro, 2005).

\section{Considerações finais}

Historicamente, o Brasil vivenciou uma estruturação de sociedade marcada pelo regime escravocrata, que avançou para a república, passando por conflituosos períodos de ditadura militar e, posteriormente, se estabelecem estruturas sociais mais democráticas. Entretanto, demarcou-se limitações no desenvolvimento social do país, por ter sido solapado por dois regimes políticos ditatoriais - em 1930 e em 1964. As duas circunstâncias trouxeram sérias implicações, tanto para a constituição social e política da sociedade brasileira, quanto para a atual conjuntura educacional, intensamente influenciada por várias demandas e desafios políticos e econômicos de cunho neoliberal (Morosini, 2005).

Nesse sentido, para se compreender em essência os modelos de estruturação curricular, as finalidades, formas de organização e de funcionamento de uma política educacional, é indispensável considerar as condições históricas, culturais, políticas e sociais de sua estrutura local. Nesse percurso compreensivo constata-se 
o potencial criativo das condições materiais, não exclusivamente como reprodução social, mas essencialmente, como um espaço de contradição e lutas (Jacob, 1997).

Portanto, conclui-se que há muitos caminhos a serem trilhados no fortalecimento e na consolidação de políticas para a educação superior brasileira com primazia pela qualidade social. Nesse campo, conclama-se à vigilância todos os sujeitos sociais, no sentido de propor e acompanhar os planos estabelecidos e ações pautados para esse nível educacional. Uma vigilância política por direitos de cidadania.

\section{Referências}

Araújo, L. (2014, Abril 22). O regime de colaboração no novo PNE [mensagem de blog]. Disponível em: http://www.sintese.org.br/j25/index.php/panora ma/blogs-e-colunistas/luiz-araujo/5898-o-regi me-de-colaboracao-no-novo-pne

Assunção, A. À. \& Oliveira, D. A.(2009). Intensificação do trabalho e saúde dos professores. Educação e Sociedade. Vol. 30, n. 107, 349- 372.

Belloni, I. (2003). Educação. In J. Bittar (org.). Governos estaduais: desafios e avanços: reflexões $e$ relatos de experiências petistas (pp. 230-246). São Paulo: Ed. Fundação Perseu Abramo.

Chauí, M. (2001). Escritos sobre a universidade. São Paulo: Unesp.

Camini, L. et al. (2001). Educação pública de qualidade social: conquistas e desafios. Petrópolis: Vozes.

Cury, C. R. J. (2002). A educação básica no Brasil. Educação e Sociedade, Vol 23, n.80, 169-201.

Dourado, L.F., Oliveira, J.F. \& Santos, C.A. (2007). A qualidade da educação: conceitos e definições. Brasília, DF: INEP.

Ferreira, N. S. C., \& Aguiar, M. A. da S. (2001). Gestão da Educação: impasses, perspectivas $e$ compromissos. $2^{a}$ edição. São Paulo: Cortez.

Flach, S. F. (s.d.). Qualidade social da educação: uma concepção na perspectiva democrática. In Comunicação oral no IX Seminário de Pesquisa em Educação da Região Sul - IX ANPED SUL/ 2012. Disponível em:

http://www.histedbr.fae.unicamp.br/acer_h istedbr/jornada/jornada6/resumos/1318.htm

Freire, P. (2001). Política e Educação. Coleção: Questões da nossa época. 5a ed. São Paulo: Cortez Editora.

Guimarães, D.M. Barros, F.L. \& Pinto, J.R.S. (2014). Democracia na América Latina: desafios e perspectivas. Sociedade e Estado. 29 (1), pp. 15-20. doi: 10.1590/S0102-69922014000100002

Jacob, V. L. (1997). Poder do estado e poder dos docentes: um olhar sobre o movimento docente na UFPA. - Belém-PA: SPEP/GRAPHITE.

Machado, L. R. S.(2006). Instituições de Educação Superior com Qualidade Social. In: Irene Jeanete Lemos Gilberto. (Org.). Universidade em Tempos de Desafio. (pp. 11-27). Santos: Editora Universitária Leopoldianum.
Morosini, M. C.(2005). O ensino superior no Brasil. In: M. Stephanou. \& M.H.L.C. Bastos. (Orgs.). Histórias e memórias da educação no Brasil. vol. III: século XX. - Petrópolis, RJ: Vozes.

Oliveira, D. A. (2004). A reestruturação do trabalho docente: precarização e flexibilização. Educação e Sociedade. Vol.25, n. 89, 1127-1144.

Paro, V. H. (2001). Escritos sobre educação. São Paulo: Xamã.

Paro, V. H. (2005). Gestão democrática da escola pública. São Paulo: Ática, 2005.

Paro, V. H. (2007). Gestão escolar, democracia e qualidade do ensino. São Paulo: Ática.

Ristoff, D. (2008). Educação Superior no Brasil - 10 anos pós-LDB: da expansão à democratização In: M. Bittar; J. F. Oliveira \& M. Morosini, (Orgs). Educação Superior no Brasil: 10 Anos Pós-LDB. (pp.39- 50). Brasília: INEP.

Santos, B. S. (1995). Pela mão de Alice. O social e o político na transição da pós-modernidade. São Paulo: Cortez.

Sobrinho, J. D. (2010). Democratização, qualidade e crise da educação superior: faces da exclusão e limites da inclusão. Educação \& Sociedade, 31 (113), 1223-1245. Disponível em: http://www.scielo.br/pdf/es/v31n113/10.pdf 